\title{
Microplastic Exposure Across Trophic Levels: Effects on the Host Microbiota of Freshwater Organisms
}

Javier Edo Varg ( $\sim$ jedovarg@gmail.com )

Uppsala University: Uppsala Universitet https://orcid.org/0000-0002-7895-4563

David Outomuro

University of Cincinnati

Warren Kunce

Uppsala University: Uppsala Universitet

Lukas Kuehrer

Uppsala University: Uppsala Universitet

Richard Svanbäck

Uppsala University: Uppsala Universitet

Frank Johansson

Uppsala University: Uppsala Universitet

\section{Research}

Keywords: anthropogenic stress, dragonflies, damselflies, Daphnia, pesticide, deltamethrin, ecotoxicology

Posted Date: May 24th, 2021

DOl: https://doi.org/10.21203/rs.3.rs-515763/v1

License: (9) (i) This work is licensed under a Creative Commons Attribution 4.0 International License.

Read Full License 


\section{Abstract}

\section{Background}

Microplastics are a pervasive pollutant widespread in sea- and freshwater from anthropogenic sources, and together with the presence of pesticides, they can have physical and chemical effects on aquatic organisms and on their microbiota. Few studies have explored the combined effects of microplastics and pesticides on the host microbiome, and more importantly, the effects across multiple trophic levels. In this work, we studied the effects of exposure to microplastics and the pesticide deltamethrin on the diversity and abundance of the host microbiome across a three-level food chain: daphnids-damselfly-dragonflies. Daphnids were the only organism exposed to $1 \mu \mathrm{m}$ microplastic beads, and they were fed to damselfly larvae. Those damselfly larvae were exposed to delthametrin, and then fed to the dragonfly larvae. The microbiotas of the daphnids, damselflies and dragonflies were analyzed.

Results

Our results suggest that the exposure to microplastics and deltamethrin had negative carry-over effects on the diversity and abundance of the microbiome across the three trophic levels. Moreover, the exposure to deltamethrin on the damselflies negatively affected their survival rate in the presence of the dragonfly predator, but no such effects were found on damselflies exposed to only microplastics.

\section{Conclusions}

Our study highlights the importance of evaluating ecotoxicological effects at the community level. Importantly, the indirect exposure to microplastics and pesticides through diet can potentially have bottom-up effects in the trophic webs.

\section{Introduction}

The large amount of microbes colonizing the host and covering all the mucosal surfaces such as digestive, respiratory tissues, and urogenital tracts is known as the host microbiome. The gut microbiome has drawn most attention because of its relationship with diet and its importance in many aspects of the host health and well-being (Bendtsen Bangsgaard et al. 2012, Bolnick et al. 2014b, Hanning and DiazSanchez 2015, Zha et al. 2018). For example, most studies on wild animals have shown that diet in terms of prey species has a large effect on the microbial community composition (Wang et al. 2011, Bolnick et al. 2014a, 2014b, Smith et al. 2015). Other factors such as exposure to pollutants have been also shown to have an influence on host microbiota (Merrifield et al. 2013, Ghanbari et al. 2015, Gaulke et al. 2016, Nasuti et al. 2016, Fang et al. 2018, Yuan et al. 2019). Despite knowledge on the effects of prey consumption on the consumer's host microbiota, we know little on the potential carry-over effects of pollutants across trophic levels in predator-prey interactions. 
Microplastics (MPs), defined as plastic polymer particles smaller than $5 \mathrm{~mm}$, are pervasive emergent pollutants resulting from plastics that have been widely used in the last century, with a peak in production during the past decades (Geyer et al. 2017, Horton et al. 2017b, Jin et al. 2019, Menéndez-Pedriza and Jaumot 2020). MPs have become one of the largest wastes that are accumulated in the environment (Geyer et al. 2017, Liu et al. 2020). Plastic debris and MPs in marine ecosystems are recognized as a global threat to marine organisms (Eriksen et al. 2014, Revel et al. 2020). In recent years, a lack of studies on plastics and MPs in freshwater ecosystems has been identified as a matter of priority (Horton et al. 2017a). Indeed, studies quantifying MPs, assessing MP exposure and MP uptake in freshwater organisms have been performed (de Sá et al. 2018), demonstrating that MPs could have direct effects on the organisms, e.g., on life history traits (Besseling et al. 2014, Au et al. 2015, de Sá et al. 2018). Moreover, the presence of ingested MPs in the gut imposes a threat as potential carriers of adsorbed hydrophobic organic chemicals or persistent organic pollutants that might be transferred to the organism (McCormick et al. 2014, Horton et al. 2018). This might result in additive or synergic activities between MPs and other environmental pollutants such as pesticides, and MPs and pesticides might therefore have physical and chemical effects on the host microbiota of aquatic organisms after ingestion (Jeong et al. 2016, Liu et al. 2020). For example, Jin et al. (2019) showed that MPs caused changes in the microbiota of mice, and these microbiome changes were suggested to affect metabolic disorders in the host. Nasuti et al. (2016) showed that the pyrethroid permethrin reduced the abundance of several microbe groups in the guts of rats. However, few studies have focused on non-model organisms and on the combined effects of MPs and pesticides in the host and its microbiome.

Importantly, MPs and pesticides can have effects across trophic levels (Carbery et al. 2018, Athey et al. 2020, Costa et al. 2020, Elizalde-Velázquez et al. 2020). Changes in the nutrients and in the carbon source can modify the microbes in the environment (Townsend et al. 1998, Cabrerizo et al. 2019). It has been shown that the microbiome is highly affected by food availability as well as habitat disturbance (Roger et al. 2016, Foster et al. 2017), which potentially could result in bottom-up control of the microbes, i.e., affecting the microbiome of organisms higher up in the food chain (Fahnenstiel et al. 1998, Carrillo et al. 2008, de Vos 2017, Li et al. 2020). Pervasive pollutants such as MPs could be colonized and used as a carbon source by some microorganism which in turn could interact with other stressors (Zettler et al. 2013, Jacquin et al. 2019, Amaral-Zettler et al. 2020). Hence, MPs colonized by microorganisms could interact with pesticides affecting bottom-up food web dynamics, but few studies are available on such interactions.

In this work, we examined the effects of exposure to MPs, with and without an additional disturbance induced by a sudden exposure to the pesticide deltamethrin (DMT). To examine this, we studied the changes in the diversity and abundance of the host microbiome in a three-level food chain: planktonic crustaceans (daphnids), predatory damselfly larvae and top predatory dragonfly larvae. Our manipulation of pollutants occurred at the first (MPs) and second (DMT) food chain levels. In addition, we estimated the survival of the damselfly larvae to the dragonfly top predator. We predicted effects on the diversity and abundance of the host microbiome across all food chain levels. MPs would behave as substrates for the microbial community, leading to changes in the microbial diversity and abundance. In the presence of 
pesticides, we predicted that the microbial diversity and abundance would decrease. For the combined exposure to MPs and pesticide we predicted intermediate effects on the diversity and abundance of the microbiome compared to those observed in the exposures to MPs and pesticide alone: the MPs might sequester the pesticide by adsorption. We also predicted higher predation rate when the damselflies were expose to MPs or the pesticide alone, due respectively to a high accumulation of MPs in the body or intoxication of the pesticide. However, when the damselflies were expose to both MPs and the pesticide, we hypothesized that the effect of the pesticide might be attenuated by the adsorption capacity of the MPs, resulting in lower predation rates than the exposure to MPs or pesticide alone.

\section{Material And Methods \\ 2.1. Pesticide used}

The pesticide DMT was chosen for examining effects on the microbiome. This pesticide is a pyrethroid that is extensively applied in agriculture, aquaculture and forestry, as a pest control (Mestres and Mestres 1992, Hong et al. 2020). DMT is known for its neurotoxic effects, acting mainly in the voltage-gated $\mathrm{Na}^{+}$ channels of the nervous system (Mestres and Mestres 1992, Hong et al. 2020), and in secondary targets involved in signal transduction (Toshio 1992, Toumi et al. 2015). DMT has been shown to have negative effects on a variety of organisms including mammals and birds, and it is also highly toxic to aquatic organisms such as fish and aquatic invertebrates (Dawood et al. 2020, Hong et al. 2020). Moreover, the effect of DMT in non-target organisms might be worsened due to the presence of other stressors, nutritional deficiencies, or other pollutants such as MPs (Menéndez-Pedriza and Jaumot 2020). Studies on combined effects of MPs and DMT are rare (Horton et al. 2018, Felten et al. 2020), and do not take into account the host microbiome.

\subsection{Study species}

The following species were used as the three-level food chain: the planktonic crustacean Daphnia magna Straus, 1820 as the resource level, the damselfly larva Ischnura elegans (Vander Linden, 1820) as the intermediate predator, and the dragonfly larva Aeshna cyanea (Müller, 1764) as the top predator. Daphnids are part of the diet of damselflies and damselflies occur in the diet of dragonflies (Pritchard 1964, Blois 1985). All three species co-occur in waters in northern Europe (F. Johansson, unpublished).

\subsection{Experimental design}

Two main experiments were performed to examine how the effects of exposure to pollutants at lower trophic levels affects the microbiome and how these effects are transferred to higher trophic levels. In the first experiment, daphnids were exposed to MPs, DMT and a combination of MPs and DMT. The control group was not exposed to either MPs or DMT. The daphnid microbiome was analyzed in this experiment.

In the second experiment, the effects of MPs and DMT were studied in the three trophic food chain (Fig. 1). Daphnids were divided in two groups, one exposed to MPs and one used as a control. These daphnids were then used to fed damselflies. Half of the damselflies were exposed to DMT simulating a 
sudden rainstorm causing a flush of pesticides potentially affecting freshwater organisms, resulting in the following four treatments: damselflies fed on control daphnids (Control group), damselflies fed on control daphnids and exposed to DMT (DMT group), damselflies fed on daphnids exposed to MPs (MPs group), and damselflies exposed to DMT and fed on daphnids exposed to MPs (combined exposure group). Finally, the damselflies from the four treatments, were offered to a dragonfly top predator. The microbiome of the damselflies and the dragonflies was analyzed, and the survival of the damselflies recorded. The dragonfly predator was not exposed to DMT because the aim of this experiment was to examine the sole effects of the transfer of MPs and DMT on the microbiome of the top trophic level.

\subsection{Pre-experimental setup}

Laboratory cultured $D$. magna that had been kept for 5 years were used as the prey in the experiments. Prior to the start of the experiments, Daphnia were grown in a $70 \mathrm{~L}$ tank in aerated dechlorinated tap water. The temperature was $20 \pm 1^{\circ} \mathrm{C}$, and photoperiod was $16 \mathrm{~h} \mathrm{~L}$ : $8 \mathrm{~h} \mathrm{D}$. Before being used in the experiments, groups of 15 daphnids were transferred to $2 \mathrm{~L}$ plastic vessels with $1.2 \mathrm{~L}$ of dechlorinated tap water where they were fed Raphidocelis subcapitata algae. The algae were grown in modified Wright's cryptophyte (MWC) medium (Guillard and Lorenzen 1972) in $1 \mathrm{~L}$ flasks stirred overnight.

Eggs of the damselfly I. elegans were obtained from 10 mated females collected with a butterfly net in Uppsala, Sweden $(59.843715,17.666730)$. The eggs were hatched in the laboratory and after hatching larvae were randomly mixed and added to five plastic rearing containers ( $25 \mathrm{~cm}$ diameter, $12 \mathrm{~cm}$ height). The rearing containers were filled with $2 \mathrm{~L}$ of aged tap water and kept at $20^{\circ} \mathrm{C}$. Damselfly larvae were fed daily with brine shrimp Artemia salina (Linnaeus, 1758) and D. magna. All larvae were kept in the rearing containers until used in the experiments.

The dragonfly A. cyanea was sampled at the larval stage using a hand net in a pond close to Uppsala, Sweden $(59.852864,17.472441)$. A total of 80 larvae were collected and transported to the laboratory in a $10 \mathrm{~L}$ plastic container with water and vegetation from the pond. In the laboratory, the dragonfly larvae were redistributed individually into small plastics containers $(400 \mathrm{ml})$ with $150 \mathrm{~mL}$ of a mixture of tap water (conditioned tap water filled up 2 days before) and pond water. A branch of vegetation from the pond and a small stone were added to each container for habitat enrichment. Water temperature was kept at $20^{\circ} \mathrm{C}$. Dragonfly larvae were fed every other day with two Chironomous riparius (Meigen, 1804) and with D. magna.

\subsection{Experimental setup}

\subsubsection{Concentration of MPs and DMT}

In the environment, the highest reported waterborne concentration of MPs $>80 \mu \mathrm{m}$ exceeds 100000 particles $\mathrm{m}^{-3}$. However, due to the size of the MPs and the complexity of MP sampling, there is no comprehensive data of MPs $<333 \mu \mathrm{m}$ (Cole et al. 2014, 2015). Due to constant fragmentation the size of MPs would decrease and the particle concentration will increase. Therefore, a concentration and size of 
$7.8^{\star} 10^{5}$ particles $/ \mathrm{mL}$ of $3 \mu \mathrm{m}$ MPs spheres was used (Polybead Microspheres, CAS\# 0009003536, Polysciences, Inc.).

Pyrethroid pesticides and DMT have a half-life that ranges from 25 to 72 days depending on the substrate, and they have been found in concentrations of $0.04-24 \mu \mathrm{g} / \mathrm{L}$ in agricultural areas, $0.1-6.0$ $\mu \mathrm{g} / \mathrm{L}$ in water bodies and up to $100 \mu \mathrm{g} / \mathrm{L}$ in bottom sediments (Mestres and Mestres 1992, Pawlisz et al. 1998, Liess et al. 1999, Beketov et al. 2013, Toumi et al. 2015). Other studies used a sub-lethal dose of DMT at concentrations of $0.25 \mu \mathrm{g} / \mathrm{L}$ to $15 \mu \mathrm{g} / \mathrm{L}$ (Toumi et al. 2015, Dawood et al. 2020, Hong et al. 2020). The chosen concentration of DMT was therefore $0.2 \mu \mathrm{g} / \mathrm{L}$ of aerated DMT.

\subsubsection{Daphnia}

At the start of the experiment daphnids from the $2 \mathrm{~L}$ plastic vessels were moved to two $6 \mathrm{~L}$ glass containers, with approximately 2000 individuals per container. One container was exposed to MPs and the other container held only dechlorinated tap water (control). A previous study (Rist et al. 2017) suggested that a complete egestion in Daphnia does not occur within $24 \mathrm{~h}$, meaning that in 48 hours the animals will start a second round of MPs ingestion. The Daphnia were therefore exposed to MPs for 48 hours. After this treatment, five daphnids from the MPs treatment and five from the control treatment were exposed to $0.2 \mu \mathrm{g} / \mathrm{L}$ aerated DMT solution individually for 24 hours. This created four treatments: control, exposure to MPs, exposure to DMT and exposure to both MPs and DMT. Four replicates per treatment were used. These Daphnia were subsequently stored at $-20^{\circ} \mathrm{C}$ and used for microbiome analyses. The water was pooled per treatment and filtered with a $0.2 \mu \mathrm{m}$ filter. The filters were stored at $-20^{\circ} \mathrm{C}$ for further water microbiome analysis.

\subsubsection{Damselflies}

Before the experiment started, the damselfly larvae were placed individually in $50 \mathrm{~mL}$ glass vessels to be starved for three days. Thereafter the damselfly larvae were exposed to four treatments: control, exposure to MPs, exposure to DMT and exposure to both MPs and DMT (Fig. 1). Each treatment consisted of 40 individuals. In the control treatment, damselfly larvae were fed five Daphnia from the Daphnia control treatment. In the MPs treatment, damselfly larvae were fed five Daphnia from the Daphnia MPs treatment. The DMT treatment consisted of damselfly exposed overnight $(12 \mathrm{~h}$ ) to $0.2 \mu \mathrm{g} / \mathrm{L}$ aerated DMT solution and fed five Daphnia from the Daphnia control treatment. Finally, the combined exposure treatment of MPs and DMT consisted of overnight exposed damselfly larvae to $0.2 \mu \mathrm{g} / \mathrm{L}$ aerated DMT solution, followed by feeding them with five Daphnia from the Daphnia MPs treatment. In all treatments, each damselfly larva was allowed to feed on the five Daphnia for four hours. All the damselfly larvae ate all the Daphnia provided. After this experiment, a minimum of three damselfly larvae from each treatment were stored at $-20^{\circ} \mathrm{C}$ for further microbiome analysis.

\subsubsection{Dragonflies}

Dragonfly larvae were placed in individual plastic containers (9 cm height, $7 \mathrm{~cm}$ width, $7 \mathrm{~cm}$ length) and starved for four days prior to the start of the experiment. Each container was filled with $200 \mathrm{ml}$ of aged 
tap water and had a small stone that served as a perch for the dragonfly. A second set of damselfly larvae were given the same four experimental treatments as described in the previous section (control, MPs, DMT and combined MPs and DMT) and subsequently used for serving as prey for the dragonfly larvae (Fig. 1). Each damselfly was rinsed with aerated dechlorinated tap water two hours before being used in this experiment. Hence, the dragonfly larvae were not exposed to the treatments per se, it was only the prey (damselfly larvae) that received these treatments. Within each individual dragonfly container, 3 damselfly larvae from the same treatment were added. Predation was noted upon 10, 20, 30, 60, 120, 180, 840 and 1440 minutes after adding the three damselfly larvae. Fifteen replicates were run for each treatment. After the 1440 minutes, the dragonfly larvae were stored at $-20^{\circ} \mathrm{C}$ and later used for microbiome analysis.

\subsection{DNA extraction and library preparation}

The whole microbiome was extracted and analyzed for all the Daphnia and damselfly after rinsing them with Milli Q water to avoid microbes from the water. The dragonfly larvae were dissected to be able to extract the whole gut microbiome. Larvae were first rinsed with Milli Q water, decapitated and dissected with a sharp sterile blade to have access to the larvae gut. Using DNeasy Powersoil (Qiagen, No./ID: 12888-10), DNA was extracted from the three species, and from the stored $0.2 \mu \mathrm{m}$ filters used to filter the water. The manufacture's protocol was followed with an additional incubation at $65^{\circ} \mathrm{C}$ for $10 \mathrm{~min}$ after adding the $\mathrm{C} 1$ solution and additional 30 minutes of the bead homogenizer step. The $16 \mathrm{~S}$ ribosomal RNA gene was amplified in a two-step PCR using primer pair 515F and 805R that flanks the hypervariable region V4. For the first step, PCRs were performed in triplicate using Phusion High-Fidelity DNA polymerase (Thermo Fisher Scientific, No./ID: F-530XL). Thirty cycles were performed following the Phusion polymerase protocol. Negative controls were run during DNA extraction and 16S PCR amplification to check for contamination. Triplicate PCR products of each sample were pooled and subsequently purified using AMPure XP magnetic beads (Beckman Coulter, No./ID: A63882). For the second step, lllumina adaptor sequences and barcodes were attached to the PCR primers to provide each sample with a unique identifier. Samples were then purified again using magnetic beads. An equal concentration of DNA from each sample was pooled and run through agarose gel. Then, the 400-500 bp band was excised and purified using the QIAquick gel extraction kit (Qiagen, No./ID: 28104). PCR products were sequenced on IlluminaMiSeq to obtain 250 bp paired-end reads at Science for Life Laboratory (SciLifeLab, Uppsala, Sweden).

\subsection{Sequencing data analysis}

The Daphnia, damselfly, dragonfly and the water microbiome ( $0.2 \mu \mathrm{m}$ filtered water) amplicon sequence variant (ASV) tables were created using demultiplexed data from the SciLifeLab and following the DADA2 pipeline 1.8 (Callahan et al. 2016). The alfa diversity and the most abundant phyla were calculated using the R packages lattice (Sarkar, 2008) and MASS (Venables and Ripley 2002). A diversity analysis (phylogenetic, Shanon and Chao) was performed to obtain ASV phylogenetic biodiversity, ASV evenness and ASV richness, using the R packages fossil (Vavrek 2011), vegan (Oksanen et al. 2018), ape (Paradis and Schliep 2019) and picante (Kembel et al. 2010). To test the effects to the exposure to MP and DMT 
on the microbiome, linear models were carried out using the diversity indexes as the response variable and the exposure to MPs and DMT (presence/absence) as fixed effects. Due to lack of normality, a permutation analysis was performed with 9999 permutations to confirm the robustness of the parametric model (Hothorn et al. 2006). A post-hoc test was carried out for pairwise comparisons using the $\mathrm{R}$ packages FSA(Ogle et al. 2020) and rcompanion (Mangiafico 2020).

The beta diversity was assessed using Permutational Multivariate Analysis of Variance (PERMANOVA) using the R package vegan (Oksanen et al. 2019). The ASV distance matrix was used as a response variable, including the exposure to MP and DMT (presence/absence) as factors. To observe how the microbial communities cluster between treatments, a Principal Coordinates Analysis (PCoA) was performed. A Multivariate Analysis of Variance (MANOVA) was also run using the relative abundances of the main six phyla as a response variable, and MPs and DMT as fixed factors. To observe the effects of MPs and DMT in the relative abundance of each main phyla, Generalized Linear Models (GLM) with a quasi-Poisson family were performed. All the statistical analyses were executed in R statistical Computing Language 3.6.2 ( $\mathrm{R}$ Core Team 2020). The phylogenetic tree, and the taxonomy plots were created using Qiime 1.9.9 (Caporaso et al. 2012).

\subsection{Predation analysis}

The effects of the different exposure treatments on the damselfly survival against dragonfly predation at $10,20,30,60,120,180,840$ and 1440 minutes were analyzed using Generalized Linear Mixed Models (GLMM) with multivariate normal random effects, using Penalized Quasi-Likelihood. The response variable was entered as counts per vessel of living and predated damselfly larvae for each time period. Time was entered as a covariate, and the exposures (presence/absence) to MP and DMT were entered as fixed factors. The dragonfly ID was entered as a random effect. Finally, to account for repeated measurements an autocorrelation structure of order one was entered, with time as a continuous covariate and dragonfly ID as a grouping effect. The model was performed using the R packages MASS (Venables and Ripley 2002) and nlme (Pinheiro et al. 2020). A post-hoc test was performed to observe differences between treatments using the R package emmeans (Lenth et al. 2020).

\section{Results}

\subsection{Alpha and beta diversity of the host microbiome}

In the daphnid microbiome, the Chao diversity index was negatively affected by the exposure to DMT (Table 1, Fig. 2). For the Shannon diversity index, the combined exposure to MPs and DMT had a significant positive effect on the microbial diversity (Table 1, Fig. 2). The Phylogenetic diversity index only showed a marginally non-significant effect by the exposure to DMT (Table 1, Fig. 2). The post hoc analyses showed that for the Shannon index, the MPs treatment was significantly different compared to the combination of MPs and DMT (Fig. 2). In addition, there were some marginal non-significant differences between treatments in the Shannon and Chao indexes (Fig. 2). 
Table 1

Effects of exposure to microplastics (MPs) and deltamethrin (DMT) on the host microbiome of Daphnia, damselfly larvae and dragonfly larvae. The host microbiome was studied as Alpha (Chao, Shannon, Phylogenetic) and Beta diversity (Permanova). Significant and marginally non-significant p-values are highlighted in bold.

\begin{tabular}{|c|c|c|c|c|}
\hline Organism & Variable & MPs & DMT & MPs $x$ DMT \\
\hline \multirow[t]{12}{*}{ Daphnia } & Chao & & & \\
\hline & $F_{3,13}$ & 0.623 & 6.940 & 1.135 \\
\hline & $\mathrm{p}$-value & 0.444 & 0.021 & 0.306 \\
\hline & Shannon & & & \\
\hline & $\mathrm{F}_{3,13}$ & 0.523 & 0.482 & 12.057 \\
\hline & $\mathrm{p}$-value & 0.482 & 0.5 & 0.004 \\
\hline & Phylogenetic & & & \\
\hline & $F_{3,13}$ & 0.053 & 3.347 & 0.194 \\
\hline & p-value & 0.821 & 0.09 & 0.666 \\
\hline & Permanova & & & \\
\hline & $F_{3,13}$ & 0.604 & 1.356 & 2.729 \\
\hline & $\mathrm{p}$-value & 0.696 & 0.248 & 0.027 \\
\hline \multirow[t]{11}{*}{ Damselfly } & Chao & & & \\
\hline & $\mathrm{F}_{3,20}$ & 20.281 & 5.344 & 0.787 \\
\hline & $\mathrm{p}$-value & $<0.001$ & 0.032 & 0.386 \\
\hline & Shannon & & & \\
\hline & $\mathrm{F}_{3,20}$ & 16.244 & 3.059 & 0.111 \\
\hline & $\mathrm{p}$-value & $<0.001$ & 0.101 & 0.743 \\
\hline & Phylogenetic & & & \\
\hline & $F_{3,20}$ & 16.226 & 2.02 & 1.67 \\
\hline & $\mathrm{p}$-value & $<0.001$ & 0.171 & 0.211 \\
\hline & Permanova & & & \\
\hline & $\mathrm{F}_{3,20}$ & 6.876 & 1.815 & 0.888 \\
\hline
\end{tabular}




\begin{tabular}{|c|c|c|c|c|}
\hline Organism & Variable & MPs & DMT & MPs x DMT \\
\hline & p-value & 0.005 & 0.159 & 0.403 \\
\hline \multirow[t]{12}{*}{ Dragonfly } & Chao & & & \\
\hline & $\mathrm{F}_{3,32}$ & 2.958 & 2.639 & 4.569 \\
\hline & p-value & 0.096 & 0.116 & 0.042 \\
\hline & Shannon & & & \\
\hline & $F_{3,32}$ & 4.308 & 2.061 & 3.436 \\
\hline & $\mathrm{p}$-value & 0.045 & 0.156 & 0.071 \\
\hline & Phylogenetic & & & \\
\hline & $\mathrm{F}_{3,32}$ & 4.666 & 1.621 & 7.136 \\
\hline & p-value & 0.041 & 0.210 & 0.013 \\
\hline & Permanova & & & \\
\hline & $\mathrm{F}_{3,32}$ & 2.626 & 0.663 & 2.467 \\
\hline & p-value & 0.016 & 0.749 & 0.020 \\
\hline
\end{tabular}

The three alpha diversity indexes of the damselfly host microbiome were all negatively impacted by the exposure to MPs (Table 1, Fig. 2). There was also a negative significant effect by the exposure to DMT on the Chao index (Table 1). Post hoc contrasts showed that for all the alpha diversity indexes, the control was significantly higher compared to other treatments (Fig. 2).

For the diversity of the dragonfly host microbiome, the exposure to MPs negatively affected the Shannon and phylogenetic indexes, whereas the effects on the Chao index were marginally non-significant (Table 1, Fig. 2). Moreover, the combined exposure of MPs and DMT negatively affected the Chao and phylogenetic indexes whereas there was only a marginally non-significant effect on the Shannon index (Table 1). Post hoc contrasts showed that the control had significant or marginally non-significant higher diversity than the other treatments, except for the phylogenetic diversity index where the control had significantly higher diversity than the exposure to MPs and DMT alone (Fig. 2).

There were distinct clusters in the host microbiome for each host species, i.e., in the daphnids, damselfly larvae and dragonfly larvae (Fig. 3). The beta diversity of the daphnids was significantly affected by the combined exposure to MPs and DMT (Table 1: Permanova). In the case of the damselfly larvae, the beta diversity was affected by the exposure to MPs (Table 1: Permanova). Finally, the beta diversity of the dragonfly larvae was affected by the exposure to MPs and the combined exposure to MPs and DMT (Table 1: Permanova). 


\subsection{Main phyla of the microbiome}

The microbiomes of the daphnids, damselflies and dragonflies were mainly dominated by the phylum Proteobacteria, and this was also the case for the water samples (Fig. 4). The six main phyla were analyzed for each species (Tables 2, 3 and 4). Four of these phyla were shared between the daphnids, the damselflies and the dragonflies and the most abundant taxa were Proteobacteria, Bacteroidetes, Cyanobacteria and Planctomycetes. The MANOVA showed no significant changes on the abundance of the main phyla of the Daphnia when exposed to MPs and/or DMT (Table 2). However, there were significant effects in the relative abundance in the individual phyla: Proteobacteria, Bacteroidetes, and Actinobacteria by the exposure to MPs, DMT and their combination; Planctomycetes by the exposure to DMT (Table 2, Fig. 4). The post hoc contrasts on the univariate relative abundances showed no significant differences between treatments (Table 5). 
Table 2

Results for the MANOVA testing the effects of exposure to microplastics (MPs) and deltamethrin (DMT) on the relative abundance of the six main microbiota phyla in the Daphnia. The univariate models testing the effects of exposure to MPs and DMT on the relative abundance of the six main microbiota phyla are also included. Significant and marginally non-significant $p$ values are highlighted in bold.

\begin{tabular}{|c|c|c|c|c|}
\hline Organism & Variable & MPs & DMT & MPs:DMT \\
\hline \multirow[t]{22}{*}{ Daphnia } & MANOVA & & & \\
\hline & Pillai & 0.413 & 0.449 & 0.447 \\
\hline & Approx $F_{6,8}$ & 0.937 & 1.088 & 1.079 \\
\hline & p-value & 0.518 & 0.443 & 0.447 \\
\hline & Proteobacteria & & & \\
\hline & $x^{2}{ }_{1,13}$ & 5.286 & 4.239 & 5.468 \\
\hline & $\mathrm{p}$-value & 0.021 & 0.039 & 0.019 \\
\hline & Bacteroidetes & & & \\
\hline & $\chi^{2}{ }_{1,13}$ & 7.399 & 5.81 & 8.009 \\
\hline & $\mathrm{p}$-value & 0.006 & 0.016 & 0.005 \\
\hline & Actinobacteria & & & \\
\hline & $x^{2} 1,13$ & 6.519 & 4.738 & 5.403 \\
\hline & p-value & 0.011 & 0.029 & 0.02 \\
\hline & Planctomycetes & & & \\
\hline & $\chi^{2}{ }_{1,13}$ & 0.075 & 3.997 & 0.101 \\
\hline & p-value & 0.784 & 0.046 & 0.75 \\
\hline & Firmicutes & & & \\
\hline & $\chi^{2}{ }_{1,13}$ & 0.399 & 0.879 & 1.154 \\
\hline & p-value & 0.528 & 0.348 & 0.283 \\
\hline & Cyanobacteria & & & \\
\hline & $x^{2}{ }_{1,13}$ & 0.049 & 0.002 & 0.476 \\
\hline & $\mathrm{p}$-value & 0.824 & 0.963 & 0.49 \\
\hline
\end{tabular}


Table 3

Results for the MANOVA testing the effects of exposure to microplastics (MPs) and deltamethrin (DMT) on the relative abundance of the six main microbiota phyla in the Damselfly. The univariate models testing the effects of exposure to MPs and DMT on the relative abundance of the six main microbiota phyla are also included. Significant and marginally non-significant $p$-values are highlighted in bold

\begin{tabular}{|c|c|c|c|c|}
\hline Organism & Variable & MPs & DMT & MPs:DMT \\
\hline \multirow[t]{22}{*}{ Damselfly } & MANOVA & & & \\
\hline & Pillai & 0.479 & 0.341 & 0.202 \\
\hline & Approx $F_{6,15}$ & 2.303 & 1.292 & 0.634 \\
\hline & p-value & 0.089 & 0.319 & 0.701 \\
\hline & Proteobacteria & & & \\
\hline & $\chi^{2} 1,20$ & 5.161 & 3.301 & 0.458 \\
\hline & p-value & 0.023 & 0.069 & 0.499 \\
\hline & Bacteroidetes & & & \\
\hline & $\chi^{2} 1,20$ & 2.07 & 1.519 & 0.332 \\
\hline & $\mathrm{p}$-value & 0.15 & 0.218 & 0.564 \\
\hline & Cyanobacteria & & & \\
\hline & $\chi^{2} 1,20$ & 7.343 & 3.851 & 0.164 \\
\hline & p-value & 0.007 & 0.050 & 0.685 \\
\hline & Planctomycetes & & & \\
\hline & $\chi^{2} 1,20$ & 5.341 & 1.746 & 0.104 \\
\hline & p-value & 0.021 & 0.186 & 0.747 \\
\hline & Unclassified & & & \\
\hline & $\chi^{2} 1,20$ & 8.057 & 2.208 & 0.216 \\
\hline & p-value & 0.004 & 0.137 & 0.642 \\
\hline & Gemmatimonadetes & & & \\
\hline & $\chi^{2} 1,20$ & 4.413 & 1.674 & 0.09 \\
\hline & p-value & 0.036 & 0.196 & 0.764 \\
\hline
\end{tabular}


Table 4

Results for the MANOVA testing the effects of exposure to microplastics (MPs) and deltamethrin (DMT) on the relative abundance of the six main microbiota phyla in the Dragonfly. The univariate models testing the effects of exposure to MPs and DMT on the relative abundance of the six main microbiota phyla are also included. Significant and marginally nonsignificant $\mathrm{p}$-values are highlighted in bold

\begin{tabular}{|c|c|c|c|c|}
\hline Organism & Variable & MPs & DMT & MPs:DMT \\
\hline \multirow[t]{22}{*}{ Dragonfly } & MANOVA & & & \\
\hline & Pillai & 0.39 & 0.084 & 0.302 \\
\hline & Approx $F_{6,27}$ & 2.877 & 0.411 & 1.949 \\
\hline & $\mathrm{p}$-value & 0.027 & 0.865 & 0.109 \\
\hline & Proteobacteria & & & \\
\hline & $\chi^{2} 1,32$ & 0.865 & 0.811 & 1.116 \\
\hline & $\mathrm{p}$-value & 0.352 & 0.368 & 0.291 \\
\hline & Cyanobacteria & & & \\
\hline & $\chi^{2} 1,32$ & 0.431 & 1.293 & 0.742 \\
\hline & $\mathrm{p}$-value & 0.511 & 0.255 & 0.389 \\
\hline & Bacteroidetes & & & \\
\hline & $\chi^{2} 1,32$ & 8.057 & 2.644 & 3.018 \\
\hline & $\mathrm{p}$-value & 0.004 & 0.104 & 0.082 \\
\hline & Planctomycetes & & & \\
\hline & $\chi^{2} 1,32$ & 1.125 & 3.868 & 3.955 \\
\hline & $\mathrm{p}$-value & 0.289 & 0.049 & 0.047 \\
\hline & Actinobacteria & & & \\
\hline & $\chi^{2} 1,32$ & 7.438 & 0.003 & 0.129 \\
\hline & $\mathrm{p}$-value & 0.006 & 0.957 & 0.72 \\
\hline & Acidobacteria & & & \\
\hline & $\chi^{2} 1,32$ & 4.07 & 2.288 & 3.207 \\
\hline & $\mathrm{p}$-value & 0.044 & 0.13 & 0.073 \\
\hline
\end{tabular}


Table 5

Post hoc contrasts on the univariate relative abundances of the main six phyla of the microbiome of Daphnia, damselflies and dragonflies, testing differences between treatments: Control, exposure to microplastics (MPs), exposure to deltamethrin (DMT), and the combined exposure to MPs and DMT. Only significant and marginally non-significant p-values are shown.

\begin{tabular}{|llll|}
\hline \multirow{2}{*}{ Daphnia } & Variable & contrast & p-value \\
& Proteobacteria & Control - MPs & 0.098 \\
\cline { 2 - 4 } & Bacteroidetes & Control - MPs & 0.075 \\
\hline \multirow{2}{*}{ Damselfly } & Proteobacteria & Control - MPs \& DMT & 0.044 \\
\cline { 2 - 4 } & Unclassified & Control - MPs & 0.047 \\
\cline { 3 - 4 } & & Control - MPs \& DMT & 0.001 \\
\hline Dragonfly & Bacteroidetes & Control - MPs & 0.036 \\
\cline { 2 - 4 } & Actinobacteria & Control - MPs & 0.045 \\
\cline { 2 - 4 } & & &
\end{tabular}

In the damselflies, the MANOVA showed marginal non-significant effects due to the exposure to MPs (Table 3). For the individual phyla the relative abundances of Proteobacteria increased significantly, while Cyanobacteria, Planctomycetes and Gemmatimonadetes decreased significantly by the exposure to MPs (Table 3, Fig. 4). In addition, the relative abundance of Cyanobacteria decreased significantly by the exposure to DMT (Table 3, Fig. 4). The relative abundance of the unclassified Phyla (constituting less that $1 \%$ of the relative abundance) increased also significantly by the exposure to MPs (Table 3, Fig. 4). The post hoc contrasts on the univariate relative abundances showed significant differences for Proteobacteria between the control and the combination of MPs and DMT, as well as for the unclassified taxa between the control and MPs, and the control and the combination of MPs and DMT (Table 5).

In the dragonflies, the MANOVA showed that the exposure to MPs significantly affected the abundance of the six main phyla (Table 4). The univariate analysis showed that the relative abundances of Bacteroidetes and Acidobacteria decreased in the MPs treatment, whereas the relative abundance of Actinobacteria increased in the MPs treatment (Table 4, Fig. 4). The Planctomycetes relative abundance was significantly affected by the DMT treatment and the two-way interaction of MPs and DMT (Table 4, Fig. 4). The post hoc contrasts on the univariate relative abundances showed significant differences for Bacteroidetes and Actinobacteria between the control and the MPs treatments (Table 5).

\subsection{Damselfly survival}

The damselfly survival decreased across time and was negatively affected by the exposure to DMT alone, but not by the exposure to MPs or the combined exposure (Table 6, Fig. 5). There were no significant twoway or three-way interaction effects between MPs, DMT and time (Table 6). 
Table 6

Results of the GLMM testing the effects of exposure to microplastics (MPs), deltamethrin (DMT) and their interaction on damselfly survival. Significant and marginally non-significant $p$-values are highlighted in bold.

\begin{tabular}{|llllllll|}
\hline Survival & MPs & DMT & Time & MPs:DMT & MPs:Time & DMT:Time & MPs:DMT:Time \\
\hline Damselfly & & & & & & & \\
\hline$F_{1,532}$ & 0.363 & 7.987 & 212.814 & 0.019 & 0.4433 & 2.353 & 0.654 \\
\hline p-value & 0.547 & $\mathbf{0 . 0 0 5}$ & $<0.001$ & 0.889 & 0.506 & 0.126 & 0.419 \\
\hline
\end{tabular}

\section{Discussion}

The main aim of this study was to investigate how the exposure to pollutants at lower trophic levels affects the microbiome at higher trophic levels, as well as how the pollutants affect predation on the intermediate level by the top predator. The microbiome was affected by the pollutants in the daphnids, the damselflies and the dragonflies. The results thus suggest that these microbiome effects were transferred from lower to higher trophic levels, showing effects and dysbiosis at the top trophic level. In addition, DMT exposure on the damselflies affected their survival rate in the presence of the predator, but no such effects were found from MPs exposure.

\subsection{Effects on the daphnia microbiome}

The diversity of the daphnid microbiome decreased in treatments with DMT and the combination of DMT and MPs. When inspecting the most abundant phyla, there were effects by the exposure to MPs, DMT and their combination on Proteobacteria, Bacteroidetes and Actinobacteria. Previous studies have shown that the microbiome of $D$. magna is primarily colonized by Proteobacteria and Bacteroidetes (Cooper and Cressler 2020) and this is consistent with the most abundant phyla found in D. magna in the present study. In vertebrates, a decrease of Bacteroidetes might be related with abnormal intestinal permeability and pro-obesity phenotype (Joly Condette et al. 2015, Fang et al. 2018, Yuan et al. 2019). The observed decrease in relative abundance of Proteobacteria and Bacteroidetes in our experiment by the exposure to MPs and DMT might have an impact on the health of $D$. magna. In support of this, previous studies on $D$. magna exposed to MPs or pesticides found certain effects on the daphnid fitness including growth, reproduction, feeding ability and mobility (Pieters et al. 2006, Besseling et al. 2014, Ma et al. 2016, Aljaibachi and Callaghan 2018, Felten et al. 2020). In the case of the exposure to MPs, the effects on fitness seem to vary depending on the size and the material of the MPs (Besseling et al. 2014, Ma et al. 2016, Rist et al. 2017, Aljaibachi and Callaghan 2018, Horton et al. 2018, Felten et al. 2020). Moreover, the combined exposure to MPs and pesticides can have diverse effects. For example, the MPs can enhance the negative effects of the pesticide in D. magna (Felten et al. 2020). The MPs can also provide more available area for the chemical to bind, changing the concentration of the pesticide in the environment and therefore decreasing the toxic effect (Horton et al. 2018). 


\subsection{Effects on the damselfly microbiome}

The microbial diversity was also affected in the damselflies. There was a clear negative effect on alpha and beta diversities caused by the ingestion of daphnids exposed to MPs. This effect in the damselfly microbiome was indirect because the damselflies were not exposed directly to the MPs. The few studies available on how MPs might affect the microbiome of aquatic organisms showed that the microbiome can be highly affected because the microorganisms can colonize the MPs (Zettler et al. 2013, AmaralZettler et al. 2020). This colonization of MPs is known to cause dysbiosis in vertebrates such as zebra fish (Qiao et al. 2019) and in invertebrates such as Collembola (Zhu et al. 2018). However, our study is the first to show indirect effects of MPs on the microbiome via transfer through the food chain. These indirect effects might be widespread and require more attention in future studies.

The direct exposure to DMT also caused changes in the Chao diversity of the damselfly microbiome. Moreover, the exposure to MPs and DMT alone had some effects on the relative abundance of some of the main phyla of the damselfly microbiome. Such effects have rarely been studied in invertebrates, but severe changes of the microbiome in vertebrates have been found when they were exposed to stressors (Xia et al. 2014, Schwartzman and Ruby 2016, Zha et al. 2018), and the change might have a large effect on the host health. For example, an increase of Proteobacteria might influence inflammation, lipid metabolism disorder, increase the susceptibility to infections, generate motor disabilities and gut diseases (Nasuti et al. 2016, Yuan et al. 2019). In our study, Proteobacteria increased in response to the exposure of MPs, increasing even more with the exposure to DMT and with the highest increase in the combined exposure to MPs and DMT. In the combined treatment, the relative abundance of all the other phyla represented less than $2 \%$ of the total relative abundance.

\subsection{Effects on the dragonfly microbiome}

The diversity of the host microbiome of the top predator, the dragonfly, decreased by the exposure to MPs alone and by the combined exposure to MPs and DMT. Moreover, there were also changes in the relative abundance of the main microbiome phyla due to the exposure to MPs and DMT, either alone or in combination. It is very important to note that the MPs treatment occurred two trophic levels below (daphnids were directly exposed to MPs), and the DMT treatment occurred one trophic level below (damselflies were directly exposed to DMT). These results show that stressors at lower levels can affect the host microbiome of organisms at higher trophic levels, including top predators that are not exposed directly to these stressors. The decrease in the diversity of the dragonfly microbiome is mirrored at the lower trophic levels. Interestingly, it was only in dragonflies that the differences in the total abundance of the main phyla were significant due to the exposure to MPs (Table 4: Manova) indicating that the effect of MPs is transferred through the food chain and maybe the MPs themselves (Carbery et al. 2018, Athey et al. 2020, Elizalde-Velázquez et al. 2020). Previous studies have suggested that the transfer of MPs through food chains might indicate a new threat due to MP contamination of soils (Huerta Lwanga et al. 2016, Zhao et al. 2016, de Souza Machado et al. 2018). This threat might be even higher in metamorphic organisms that could translocate the MPs from aquatic to terrestrial environments (Al-Jaibachi et al. 
2019). Finally, the combined treatment of MPs and DMT showed significant effects in the overall microbiome diversity, but small effects in the relative abundance of the main phyla. We argue that this effect can be due to the adsorption and absorption effects that the MPs might have (Liu et al. 2020, Menéndez-Pedriza and Jaumot 2020).

\subsection{Predation experiment: damselfly larvae survival}

The damselfly larvae were indirectly exposed to MPs and this did not cause any differences in survival. Thus, even though the MPs affected the microbiome of the damselflies, the microbiome change seemed to have no effect on predator avoidance by the damselflies. It has been previously shown that MPs could have no effect on survival (Au et al. 2015). For a complete mechanistic understanding on survival in organisms exposed to MPs, future experiments should also inspect foraging ability, escape behaviors and prey mobility rate in response to predators. In contrast to the MPs exposure, the damselflies exposed to DMT showed a higher mortality. One reason for this could be that the toxicity of DMT affects the damselfly behavior. For example, a previous study has showed that MPs in combination with a pesticide affected the swimming patterns and speed of a ciliate, Favella sp. (Athey et al. 2020). This matches with the well-known interference that DMT and other pesticides have in the voltage-gated $\mathrm{Na}^{+}$channel of the nervous system (Mestres and Mestres 1992, Hong et al. 2020). Interestingly, the interaction between MPs and DMT showed no effect on predation risk. This might be due to the binding effect that the MPs have, consequently reducing larval exposure to the pesticide (Liu et al. 2020, Menéndez-Pedriza and Jaumot 2020).

\subsection{Food chain effect}

Our results clearly showed that the effect of the exposure to pollutants at lower trophic levels affect the microbiome of organisms at higher trophic levels, despite the fact that the higher trophic levels were not directly exposed to the pollutants. This is the first study to our knowledge to show these effects. Our experimental design is somewhat artificial because in nature all three levels might be affected by DMT exposure, for example through run-off processes caused by heavy rains. We did however use the aforementioned design because we wanted to study the effect of transfers from one level to another per se, i.e., study the effect of prey exposed to MPs and DMT on the predator microbiome, instead of assessing the direct exposure on the whole system. A more optimal design that requires future investigation would be to run another experiment also applying the DMT at the level of the top predator. The treatment with MPs only on Daphnia is realistic because MPs are probably only ingested directly by the filter-feeding Daphnia and only indirectly in the second and third order predators (damselfly and dragonfly respectively).

There are plenty of studies showing that diet, in terms of which species is consumed, influences the microbiome (Ley et al. 2008, Colman et al. 2012, Bolnick et al. 2014a, Cresci and Bawden 2015, Nasuti et al. 2016, Wasielewski et al. 2016, Souza et al. 2019). In this study, we instead showed that the microbiome of a predator is influenced by the environment experienced by its prey (our treatments). We acknowledge that we do not have evidence that the microplastics are physically transferred to higher 
trophic levels. Thus, we do not know whether the effect on higher trophic levels is a direct effect from the exposure to microplastics, or if it is an indirect effect by the prey. There are two ways that a predator could be indirectly affected by the prey exposed to microplastics. First, the disturbed microbiome of the prey may be carried over and colonize the predator, similar to the effects of eating probiotics (Lazado and Caipang 2014, Marchesi et al. 2015). Second, the microbiome has been shown to affect the metabolism of the host (McCutcheon et al. 2009, Yano et al. 2015, Douglas 2018, Martin et al. 2019, Visconti et al. 2019) by producing metabolites that affect host physiology (Sekirov et al. 2010, Farmer et al. 2014, Yano et al. 2015, Visconti et al. 2019), which in turn could affect a predator's microbiome.

\section{Conclusions}

In general, the organisms on the different trophic levels harbor a diverse microbial community, and the host microbiome differed from the microbiome in the environment. Our results showed that the exposure to pesticides and microplastics at lower trophic levels had an effect on the microbiome of organisms at higher trophic levels, and whether this was caused by direct effects of pesticide/microplastic transfer or by indirect effects carried over via predation remains to be investigated. It is possible that MPs in combination with other pollutants can affect non-target organisms and their microbiome and be translocated from aquatic to soil environments via metamorphic organisms.

\section{Declarations}

\section{Ethical Approval and Consent to participate}

Ethical approval was not necessary for this project. The authors consent to participate in the project.

\section{Consent for publication}

All authors have approved the manuscript and agree with submission to Microbiome.

\section{Availability of supporting data}

Data is available on request from Javier Edo Varg at jedovarg@gmail.com. Data will be uploaded to the European nucleotide archive (ENA) after publication.

\section{Competing interests}

We confirm that this manuscript has not been published elsewhere and is not under consideration by another journal. We declare no conflict of interest associated with this publication.

\section{Funding}

This study was funded by the Swedish Research Council (VR, 2016-04015) and the Department of Ecology and Genetics. 


\section{Authors' contributions}

All the authors conceived the project and designed the experiment. L.K. and W.K. performed the experiment. J.E.V. performed the DNA extraction and DNA library preparation. J.E.V. performed the microbime analyses with advise from R.S. J.E.V. performed the statistical analysis with input from D.O. and F.J.. J.E.V. wrote this work, with important contributions from D.O. and F.J.. All co-authors contributed and approved the final version of the manuscript.

\section{Acknowledgements}

Sequencing was performed by the SNP\&SEQ Technology Platform in Uppsala, part of the National Genomics Infrastructure (NGI) Sweden and Science for Life Laboratory. The SNP\&SEQ Platform was also supported by the Swedish Research Council and the Knut and Alice Wallenberg Foundation.

\section{References}

Al-Jaibachi, R., R. N. Cuthbert, and A. Callaghan. 2019. Examining effects of ontogenic microplastic transference on Culex mosquito mortality and adult weight. Science of the Total Environment 651:871876.

Aljaibachi, R., and A. Callaghan. 2018. Impact of polystyrene microplastics on Daphnia magna mortality and reproduction in relation to food availability. PeerJ 2018.

Amaral-Zettler, L. A., E. R. Zettler, and T. J. Mincer. 2020. Ecology of the plastisphere. Nature Reviews Microbiology 18:139-151.

Athey, S. N., S. D. Albotra, C. A. Gordon, B. Monteleone, P. Seaton, A. L. Andrady, A. R. Taylor, and S. M. Brander. 2020. Trophic transfer of microplastics in an estuarine food chain and the effects of a sorbed legacy pollutant. Limnology and Oceanography Letters 5:154-162.

Au, S. Y., T. F. Bruce, W. C. Bridges, and S. J. Klaine. 2015. Responses of Hyalella azteca to acute and chronic microplastic exposures. Environmental Toxicology and Chemistry 34:2564-2572.

Beketov, M. A., B. J. Kefford, R. B. Schäfer, and M. Liess. 2013. Pesticides reduce regional biodiversity of stream invertebrates. Proceedings of the National Academy of Sciences of the United States of America 110:11039-43.

Bendtsen Bangsgaard, M. K., L. Krych, D. B. Sørensen, W. Pang, S. Nielsen, K. Josefsen, L. H. Hansen, S. J. Sørensen, and A. K. Hansen. 2012. Gut Microbiota Composition Is Correlated to Grid Floor Induced Stress and Behavior in the BALB / c Mouse 7.

Besseling, E., B. Wang, M. Lürling, and A. A. Koelmans. 2014. Nanoplastic affects growth of S. obliquus and reproduction of D. magna. Environmental Science and Technology 48:12336-12343. 
Blois, C. 1985. The larval diet of three anisopteran (Odonata) species. Freshwater Biology 15:505-514.

Bolnick, D. I., L. K. Snowberg, P. E. Hirsch, C. L. Lauber, R. Knight, J. G. Caporaso, and R. Svanbäck. $2014 a$. Individuals' diet diversity influences gut microbial diversity in two freshwater fish (threespine stickleback and Eurasian perch). Ecology Letters 17:979-987.

Bolnick, D. I., L. K. Snowberg, P. E. Hirsch, C. L. Lauber, E. Org, B. Parks, A. J. Lusis, R. Knight, J. G. Caporaso, and R. Svanbäck. 2014b. Individual diet has sex-dependent effects on vertebrate gut microbiota. Nature communications 5:4500.

Cabrerizo, M. J., J. M. Medina-Sánchez, M. Villar-Argaiz, and P. Carrillo. 2019. Interplay between resistance and resilience governs the stability of a freshwater microbial food web under multiple stressors. Science of the Total Environment 691:908-918.

Callahan, B. J., P. J. Mcmurdie, M. J. Rosen, A. W. Han, and A. J. A. 2016. Dada2. Nat Methods 13:581583.

Caporaso, J. G., C. L. Lauber, W. A. Walters, D. Berg-Lyons, J. Huntley, N. Fierer, S. M. Owens, J. Betley, L. Fraser, M. Bauer, N. Gormley, J. A. Gilbert, G. Smith, and R. Knight. 2012. Ultra-high-throughput microbial community analysis on the Illumina HiSeq and MiSeq platforms. ISME Journal 6:1621-1624.

Carbery, M., W. O'Connor, and T. Palanisami. 2018. Trophic transfer of microplastics and mixed contaminants in the marine food web and implications for human health. Environment International 115:400-409.

Carrillo, P., M. Villar-Argaiz, and J. M. Medina-Sánchez. 2008. Does microorganism stoichiometry predict microbial food web interactions after a phosphorus pulse? Microbial Ecology 56:350-363.

Cole, M., P. Lindeque, E. Fileman, C. Halsband, and T. S. Galloway. 2015. The Impact of Polystyrene Microplastics on Feeding, Function and Fecundity in the Marine Copepod Calanus helgolandicus.

Cole, M., H. Webb, P. K. Lindeque, E. S. Fileman, C. Halsband, and T. S. Galloway. 2014. Isolation of microplastics in biota-rich seawater samples and marine organisms. Scientific Reports 4:1-8.

Colman, D. R., E. C. Toolson, and C. D. Takacs-Vesbach. 2012. Do diet and taxonomy influence insect gut bacterial communities? Molecular Ecology 21:5124-5137.

Cooper, R. O., and C. E. Cressler. 2020. Characterization of key bacterial species in the Daphnia magna microbiota using shotgun metagenomics. Scientific Reports 10:1-11.

Costa, E., V. Piazza, S. Lavorano, M. Faimali, F. Garaventa, and C. Gambardella. 2020. Trophic Transfer of Microplastics From Copepods to Jellyfish in the Marine Environment. Frontiers in Environmental Science 8:1-7. 
Cresci, G. A., and E. Bawden. 2015. Gut Microbiome: What We Do and Don't Know. Nutrition in clinical practice: official publication of the American Society for Parenteral and Enteral Nutrition 30:734-46.

Dawood, M. A. O., M. F. AbdEI-kader, E. M. Moustafa, M. S. Gewaily, and S. E. Abdo. 2020. Growth performance and hemato-immunological responses of Nile tilapia (Oreochromis niloticus) exposed to deltamethrin and fed immunobiotics. Environmental Science and Pollution Research 27:11608-11617.

Douglas, A. E. 2018. Omics and the metabolic function of insect-microbial symbioses. Current Opinion in Insect Science 29:1-6.

Elizalde-Velázquez, A., A. M. Carcano, J. Crago, M. J. Green, S. A. Shah, and J. E. Cañas-Carrell. 2020. Translocation, trophic transfer, accumulation and depuration of polystyrene microplastics in Daphnia magna and Pimephales promelas. Environmental Pollution 259.

Eriksen, M., L. C. M. Lebreton, H. S. Carson, M. Thiel, C. J. Moore, J. C. Borerro, F. Galgani, P. G. Ryan, and J. Reisser. 2014. Plastic Pollution in the World's Oceans: More than 5 Trillion Plastic Pieces Weighing over 250,000 Tons Afloat at Sea. PLoS ONE 9:1-15.

Fahnenstiel, G. L., A. E. Krause, M. J. McCormick, H. J. Carrick, and C. L. Schelske. 1998. The structure of the planktonic food-web in the St. Lawrence Great Lakes. Journal of Great Lakes Research 24:531-554.

Fang, B., J. W. Li, M. Zhang, F. Z. Ren, and G. F. Pang. 2018. Chronic chlorpyrifos exposure elicits dietspecific effects on metabolism and the gut microbiome in rats. Food and Chemical Toxicology 111:144152.

Farmer, A. D., H. A. Randall, and Q. Aziz. 2014. It's a gut feeling: how the gut microbiota affects the state of mind. J Physiol 592:2981-2988.

Felten, V., H. Toumi, J. F. Masfaraud, E. Billoir, B. I. Camara, and J. F. Férard. 2020. Microplastics enhance Daphnia magna sensitivity to the pyrethroid insecticide deltamethrin: Effects on life history traits. Science of the Total Environment 714:136567.

Foster, K. R., J. Schluter, K. Z. Coyte, and S. Rakoff-Nahoum. 2017. The evolution of the host microbiome as an ecosystem on a leash. Nature 548:43-51.

Gaulke, C. A., C. L. Barton, S. Proffitt, R. L. Tanguay, and T. J. Sharpton. 2016. Triclosan exposure is associated with rapid restructuring of the microbiome in adult zebrafish. PLoS ONE 11:1-20.

Geyer, R., J. R. Jambeck, and K. L. Law. 2017. Production, use, and fate of all plastics ever made. Science Advances 3:25-29.

Ghanbari, M., W. Kneifel, and K. J. Domig. 2015. A new view of the fish gut microbiome: Advances from next-generation sequencing. Aquaculture 448:464-475. 
Guillard, R. R., and C. J. Lorenzen. 1972. Yellow-green algae with chlorophyllide C1, 2. Journal of Phycology 8:10-14.

Hanning, I., and S. Diaz-Sanchez. 2015. The functionality of the gastrointestinal microbiome in nonhuman animals. Microbiome 3:51.

Hong, Y., Y. Huang, G. Yan, H. Yin, and Z. Huang. 2020. DNA damage, immunotoxicity, and neurotoxicity induced by deltamethrin on the freshwater crayfish, Procambarus clarkii. Environmental Toxicology:1-8.

Horton, A. A., C. Svendsen, R. J. Williams, D. J. Spurgeon, and E. Lahive. 2017a. Large microplastic particles in sediments of tributaries of the River Thames, UK -- Abundance, sources and methods for effective quantifaction. Marine Pollution Bulletin 114:218-226.

Horton, A. A., M. G. Vijver, E. Lahive, D. J. Spurgeon, C. Svendsen, R. Heutink, P. M. van Bodegom, and J. Baas. 2018. Acute toxicity of organic pesticides to Daphnia magna is unchanged by co-exposure to polystyrene microplastics. Ecotoxicology and Environmental Safety 166:26-34.

Horton, A. A., A. Walton, D. J. Spurgeon, E. Lahive, and C. Svendsen. 2017b. Microplastics in freshwater and terrestrial environments: Evaluating the current understanding to identify the knowledge gaps and future research priorities. Elsevier B.V.

Hothorn, T., K. Hornik, M. A. Van De Wiel, and A. Zeileis. 2006. A lego system for conditional inference. American Statistician 60:257-263.

Huerta Lwanga, E., H. Gertsen, H. Gooren, P. Peters, T. Salánki, M. Van Der Ploeg, E. Besseling, A. A. Koelmans, and V. Geissen. 2016. Microplastics in the Terrestrial Ecosystem: Implications for Lumbricus terrestris (Oligochaeta, Lumbricidae). Environmental Science and Technology 50:2685-2691.

Jacquin, J., J. Cheng, C. Odobel, C. Pandin, P. Conan, M. Pujo-Pay, V. Barbe, A. L. Meistertzheim, and J. F. Ghiglione. 2019. Microbial ecotoxicology of marine plastic debris: A review on colonization and biodegradation by the "plastisphere." Frontiers in Microbiology 10:1-16.

Jeong, C. B., E. J. Won, H. M. Kang, M. C. Lee, D. S. Hwang, U. K. Hwang, B. Zhou, S. Souissi, S. J. Lee, and J. S. Lee. 2016. Microplastic Size-Dependent Toxicity, Oxidative Stress Induction, and p-JNK and p-p38 Activation in the Monogonont Rotifer (Brachionus koreanus). Environmental Science and Technology 50:8849-8857.

Jin, Y., L. Lu, W. Tu, T. Luo, and Z. Fu. 2019. Impacts of polystyrene microplastic on the gut barrier, microbiota and metabolism of mice. Science of the Total Environment 649:308-317.

Joly Condette, C., V. Bach, C. Mayeur, J. Gay-Quéheillard, and H. Khorsi-Cauet. 2015. Chlorpyrifos Exposure during Perinatal Period Affects Intestinal Microbiota Associated with Delay of Maturation of Digestive Tract in Rats. Journal of Pediatric Gastroenterology and Nutrition 61:30-40. 
Kembel, S. W., P. D. Cowan, M. R. Helmus, W. K. Cornwell, H. Morlon, D. D. Ackerly, S. P. Blomberg, and C. O. Webb. 2010. Picante: R tools for integrating phylogenies and ecology. Bioinformatics 26:1463-1464.

Kirstein, I. V., A. Wichels, E. Gullans, G. Krohne, and G. Gerdts. 2019. The plastisphere - Uncovering tightly attached plastic "specific" microorganisms. PLoS ONE 14:1-17.

Lazado, C. C., and C. M. A. Caipang. 2014. Mucosal immunity and probiotics in fish. Fish and Shellfish Immunology 39:78-89.

Lenth, R. V., P. Buerkner, M. Herve, J. Love, H. Riebl, and H. Singmann. 2020. emmeans: Estimated Marginal Means, aka Least-Squares Means. R package version 1.4.6.

Ley, R. E., C. A. Lozupone, M. Hamady, R. Knight, and J. I. Gordon. 2008. Worlds within worlds: Evolution of the vertebrate gut microbiota. Nature Reviews Microbiology 6:776-788.

Li, G., B. Yin, J. Li, J. Wang, W. Wei, D. I. Bolnick, X. Wan, B. Zhu, and Z. Zhang. 2020. Host-microbiota interaction helps to explain the bottom-up effects of climate change on a small rodent species. ISME Journal 14:1795-1808.

Liess, M., R. Schulz, M. H. D. Liess, B. Rother, and R. Kreuzig. 1999. Determination of insecticide contamination in agricultural headwater streams. Water Research 33:239-247.

Liu, P., X. Zhan, X. Wu, J. Li, H. Wang, and S. Gao. 2020. Effect of weathering on environmental behavior of microplastics: Properties, sorption and potential risks. Chemosphere 242:125193.

Ma, Y., A. Huang, S. Cao, F. Sun, L. Wang, H. Guo, and R. Ji. 2016. Effects of nanoplastics and microplastics on toxicity, bioaccumulation, and environmental fate of phenanthrene in fresh water. Environmental Pollution 219:166-173.

Mangiafico, S. 2020. rcompanion: Functions to Support Extension Education Program Evaluation. R package version 2.3.25.

Marchesi, J. R., D. H. Adams, F. Fava, G. D. a Hermes, G. M. Hirschfield, G. Hold, M. N. Quraishi, J. Kinross, H. Smidt, K. M. Tuohy, L. V Thomas, E. G. Zoetendal, and A. Hart. 2015. The gut microbiota and host health: a new clinical frontier. Gut :1-10.

Martin, A. M., E. W. Sun, G. B. Rogers, and D. J. Keating. 2019. The influence of the gut microbiome on host metabolism through the regulation of gut hormone release. Frontiers in Physiology 10:1-11.

McCormick, A., T. J. Hoellein, S. A. Mason, J. Schluep, and J. J. Kelly. 2014. Microplastic is an abundant and distinct microbial habitat in an urban river. Environmental Science and Technology 48:11863-11871.

McCutcheon, J. P., B. R. McDonald, and N. A. Moran. 2009. Convergent evolution of metabolic roles in bacterial co-symbionts of insects. Proceedings of the National Academy of Sciences of the United States 
of America 106:15394-9.

Menéndez-Pedriza, A., and L. Jaumot. 2020. Microplastics: A Critical Review of Sorption Factors ,. Toxics $8: 1-40$.

Merrifield, D. L., B. J. Shaw, G. M. Harper, I. P. Saoud, S. J. Davies, R. D. Handy, and T. B. Henry. 2013. Ingestion of metal-nanoparticle contaminated food disrupts endogenous microbiota in zebrafish (Danio rerio). Environmental Pollution 174:157-163.

Mestres, R., and G. Mestres. 1992. Deltamethrin: Uses and Environmental Safety. Page Springer-Verlag.

Nasuti, C., M. M. Coman, R. A. Olek, D. Fiorini, M. C. Verdenelli, C. Cecchini, S. Silvi, D. Fedeli, and R. Gabbianelli. 2016. Changes on fecal microbiota in rats exposed to permethrin during postnatal development. Environmental Science and Pollution Research 23:10930-10937.

Ogle, D. H., P. Wheeler, and A. Dinno. 2020. FSA: Fisheries Stock Analysis. R package version 0.8.30.

Oksanen, J., G. Blanchet, M. Friendly, R. Kindt, P. Legendre, D. McGlinn, P. R. Minchin, R. B. O’Hara, G. L. Simpson, P. Solymos, M. H. H. Stevens, E. Szoecs, and H. Wagner. 2019. vegan: Community Ecology Package. R package version 2.5-6.

Paradis, E., and K. Schliep. 2019. Ape 5.0: An environment for modern phylogenetics and evolutionary analyses in R. Bioinformatics 35:526-528.

Pawlisz, A. V., J. Busnarda, A. McLauchlin, P. Y. Caux, and R. A. Kent. 1998. Canadian water quality guidelines for deltamethrin. Environmental Toxicology and Water Quality 13:175-210.

Pieters, B. J., T. Jager, M. H. S. Kraak, and W. Admiraal. 2006. Modeling responses of Daphnia magna to pesticide pulse exposure under varying food conditions: Intrinsic versus apparent sensitivity. Ecotoxicology 15:601-608.

Pinheiro, J., D. Bates, S. DebRoy, D. Sarkar, and R. C. Team. 2020._nlme: Linear and Nonlinear Mixed Effects Models_. R package version 3.1-145.

Pritchard, G. 1964. the Prey of Dragonfly Larvae (Odonata; Anisoptera) in Ponds in Northern Alberta. Canadian Journal of Zoology 42:785-800.

Qiao, R., Y. Deng, S. Zhang, M. B. Wolosker, Q. Zhu, H. Ren, and Y. Zhang. 2019. Accumulation of different shapes of microplastics initiates intestinal injury and gut microbiota dysbiosis in the gut of zebrafish. Chemosphere 236:124334.

R Core Team. 2020. A language and environment for statistical computing. R Foundation for Statistical Computing, Vienna, Austria. 
Revel, M., A. Châtel, H. Perrein-Ettajani, M. Bruneau, F. Akcha, R. Sussarellu, J. Rouxel, K. Costil, P. Decottignies, B. Cognie, F. Lagarde, and C. Mouneyrac. 2020. Realistic environmental exposure to microplastics does not induce biological effects in the Pacific oyster Crassostrea gigas. Marine Pollution Bulletin 150:110627.

Rist, S., A. Baun, and N. B. Hartmann. 2017. Ingestion of micro- and nanoplastics in Daphnia magna Quantification of body burdens and assessment of feeding rates and reproduction. Environmental Pollution 228:398-407.

Roger, F., S. Bertilsson, S. Langenheder, O. A. Osman, and L. Gamfeldt. 2016. Effects of multiple dimensions of bacterial diversity on functioning, stability and multifunctionality. Ecology 97:2716-2728.

de Sá, L. C., M. Oliveira, F. Ribeiro, T. L. Rocha, and M. N. Futter. 2018. Studies of the effects of microplastics on aquatic organisms: What do we know and where should we focus our efforts in the future? Science of the Total Environment 645:1029-1039.

Schwartzman, J. A., and E. G. Ruby. 2016. Stress as a Normal Cue in the Symbiotic Environment. Trends in Microbiology 24:414-424.

Sekirov, I., S. L. Russell, L. Caetano M Antunes, and B. B. Finlay. 2010. Gut microbiota in health and disease. Physiological Reviews 90:859-904.

Smith, C. C. R., L. K. Snowberg, J. Gregory Caporaso, R. Knight, and D. I. Bolnick. 2015. Dietary input of microbes and host genetic variation shape among-population differences in stickleback gut microbiota. ISME Journal 9:2515-2526.

de Souza Machado, A. A., W. Kloas, C. Zarfl, S. Hempel, and M. C. Rillig. 2018. Microplastics as an emerging threat to terrestrial ecosystems. Global Change Biology 24:1405-1416.

Souza, R. S., F. Virginio, T. I. S. Riback, L. Suesdek, J. B. Barufi, and F. A. Genta. 2019. Microorganismbased larval diets affect mosquito development, size and nutritional reserves in the yellow fever mosquito aedes aegypti (Diptera: Culicidae). Frontiers in Physiology 10.

Toshio, N. 1992. Nerve membrane Na+ channels as targets of insecticides. Trends in Pharmacological Sciences 13:236-241.

Toumi, H., M. Boumaiza, M. Millet, C. M. Radetski, V. Felten, and J. F. Férard. 2015. Is acetylcholinesterase a biomarker of susceptibility in Daphnia magna (Crustacea, Cladocera) after deltamethrin exposure? Chemosphere 120:351-356.

Townsend, C. R., R. M. Thompson, A. R. Mclntosh, C. Kilroy, E. Edwards, and M. R. Scarsbrook. 1998. Disturbance, resource supply, and food-web architecture in streams. Ecology Letters 1:200-209. 
Vavrek, M. J. 2011. fossil: Palaeoecological and palaeogeographical analysis tools. Palaeontologia Electronica 14.

Venables, W. N., and B. D. Ripley. 2002. Modern Applied Statistics with S. Fourth Edition. Springer, New York.

Visconti, A., C. I. Le Roy, F. Rosa, N. Rossi, T. C. Martin, R. P. Mohney, W. Li, E. de Rinaldis, J. T. Bell, J. C. Venter, K. E. Nelson, T. D. Spector, and M. Falchi. 2019. Interplay between the human gut microbiome and host metabolism. Nature Communications 10.

de Vos, W. M. 2017. Microbe profile: Akkermansia muciniphila: A conserved intestinal symbiont that acts as the gatekeeper of our mucosa. Microbiology (United Kingdom) 163:646-648.

Wang, Y., T. M. Gilbreath, P. Kukutla, G. Yan, and J. Xu. 2011. Dynamic gut microbiome across life history of the malaria mosquito anopheles gambiae in Kenya. PLoS ONE 6:1-9.

Wasielewski, H., J. Alcock, and A. Aktipis. 2016. Resource conflict and cooperation between human host and gut microbiota: implications for nutrition and health. Annals of the New York Academy of Sciences 1372:20-28.

Xia, J. H., G. Lin, G. H. Fu, Z. Y. Wan, M. Lee, L. Wang, X. J. Liu, and G. H. Yue. 2014. The intestinal microbiome of fish under starvation. BMC genomics 15:266.

Yano, J. M., K. Yu, G. P. Donaldson, G. G. Shastri, P. Ann, L. Ma, C. R. Nagler, R. F. Ismagilov, S. K. Mazmanian, and E. Y. Hsiao. 2015. Indigenous bacteria from the gut microbiota regulate host serotonin biosynthesis. Cell 161:264-276.

Yuan, X., Z. Pan, C. Jin, Y. Ni, Z. Fu, and Y. Jin. 2019. Gut microbiota: An underestimated and unintended recipient for pesticide-induced toxicity. Chemosphere 227:425-434.

Zettler, E. R., T. J. Mincer, and L. A. Amaral-Zettler. 2013. Life in the "plastisphere": Microbial communities on plastic marine debris. Environmental Science and Technology 47:7137-7146.

Zha, Y., A. Eiler, F. Johansson, and R. Svanbäck. 2018. Effects of predation stress and food ration on perch gut microbiota. Microbiome 6:1-12.

Zhao, S., L. Zhu, and D. Li. 2016. Microscopic anthropogenic litter in terrestrial birds from Shanghai, China: Not only plastics but also natural fibers. Science of the Total Environment 550:1110-1115.

Zhu, D., Q. L. Chen, X. L. An, X. R. Yang, P. Christie, X. Ke, L. H. Wu, and Y. G. Zhu. 2018. Exposure of soil collembolans to microplastics perturbs their gut microbiota and alters their isotopic composition. Soil Biology and Biochemistry 116:302-310. 
Venables, W. N. \& Ripley, B. D. (2002) Modern Applied Statistics with S. Fourth Edition. Springer, New York. ISBN 0-387-95457-0

Pinheiro J, Bates D, DebRoy S, Sarkar D, R Core Team (2020)._nlme: Linear and Nonlinear Mixed Effects Models_. R package version 3.1-145, <URL: https://CRAN.R-project.org/package=nlme>.

Russell Lenth (2020). emmeans: Estimated Marginal Means, aka Least-Squares Means. R package version 1.4.6. https://CRAN.R-project.org/package=emmeans

\section{Figures}

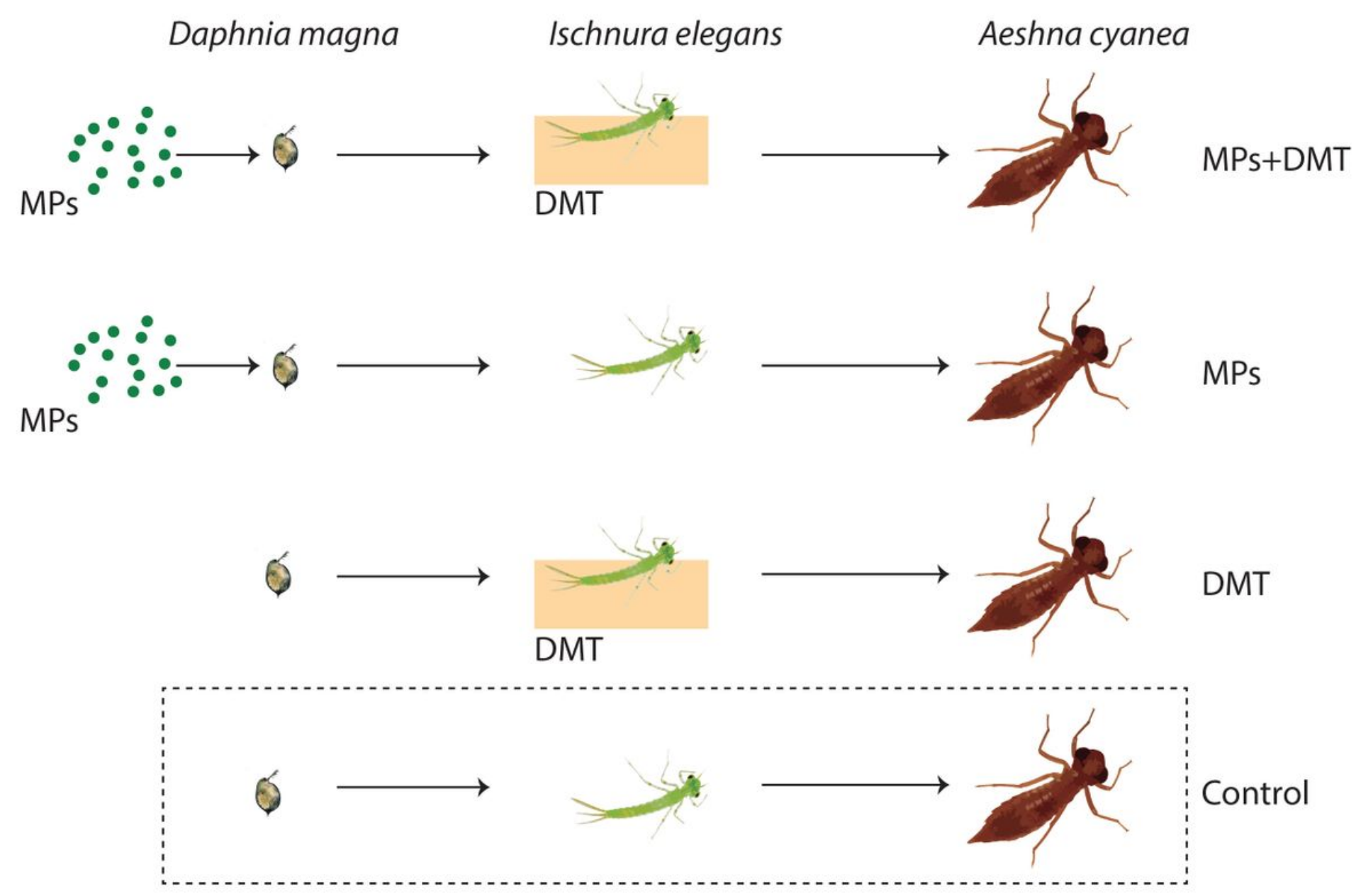

\section{Figure 1}

Overview of the experiment design showing the three-level food web. Half of the Daphnia magna were exposed to microplastics (MPs), and half were used as the control prey. The daphnids were then used to feed the damselfly Ischnura elegans. The damselflies were either exposed or not to the pesticide deltamethrin (DMT). Finally, the dragonfly Aeschna cyanea were fed with the damselflies. Neither of the three species were exposed to MPs or DMT in the Control group. 

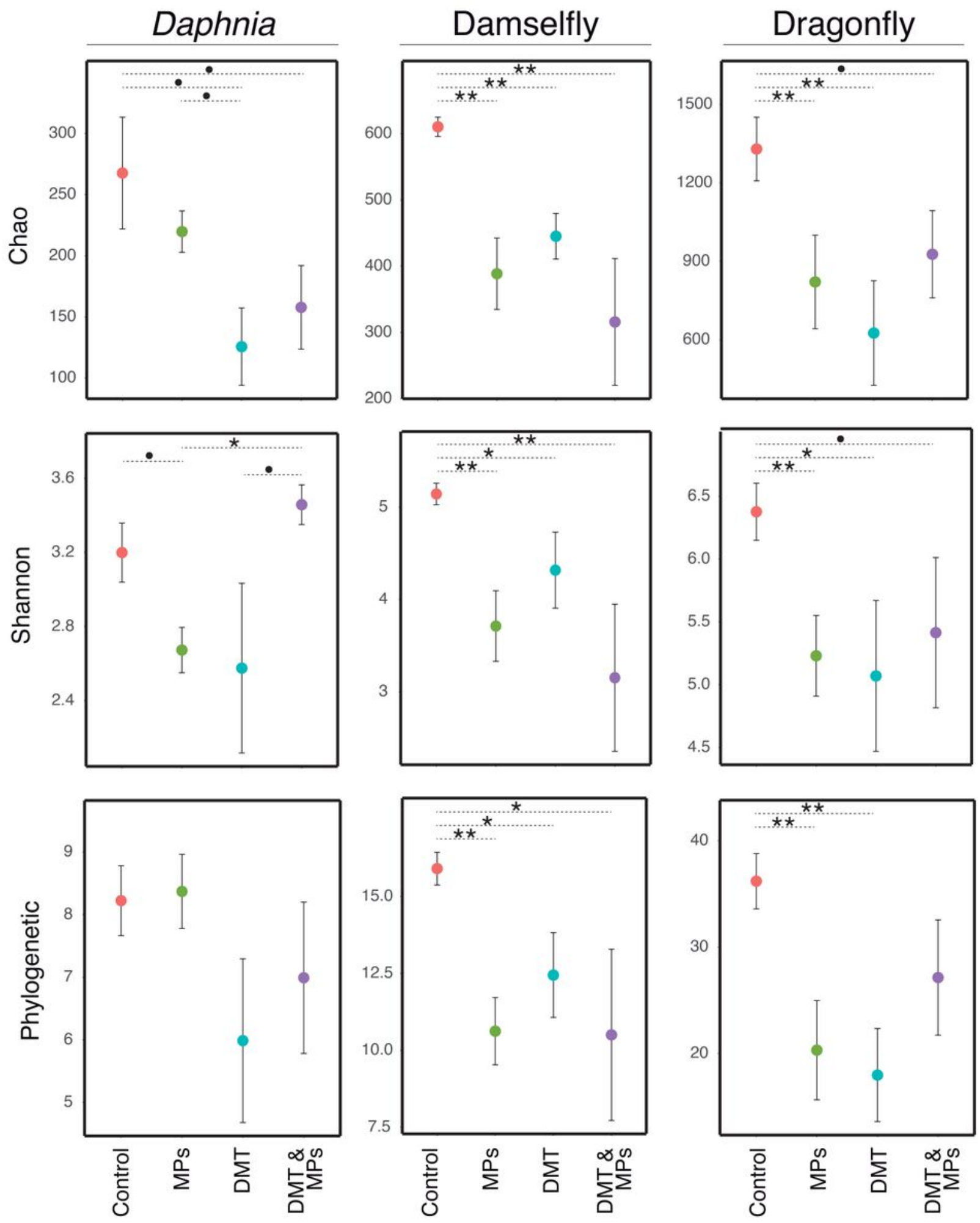

Figure 2

Diversity indexes Chao, Shannon and Phylogenic for the host microbiome of Daphnia, the damselfly larvae and the dragonfly larvae. The aquatic invertebrates were exposed to microplastics (MPs), deltamethrin (DMT) or a combination of both. The animals not exposed to either MPD or DMT were the

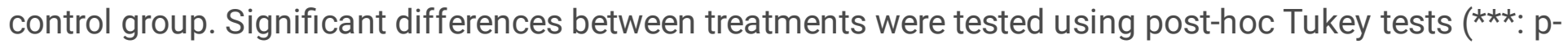
value< $0.001 ; * *$ : $0.001<$ p-value<0.01; *: p-value<0.05; $\because 0.05<$-value<0.09). 

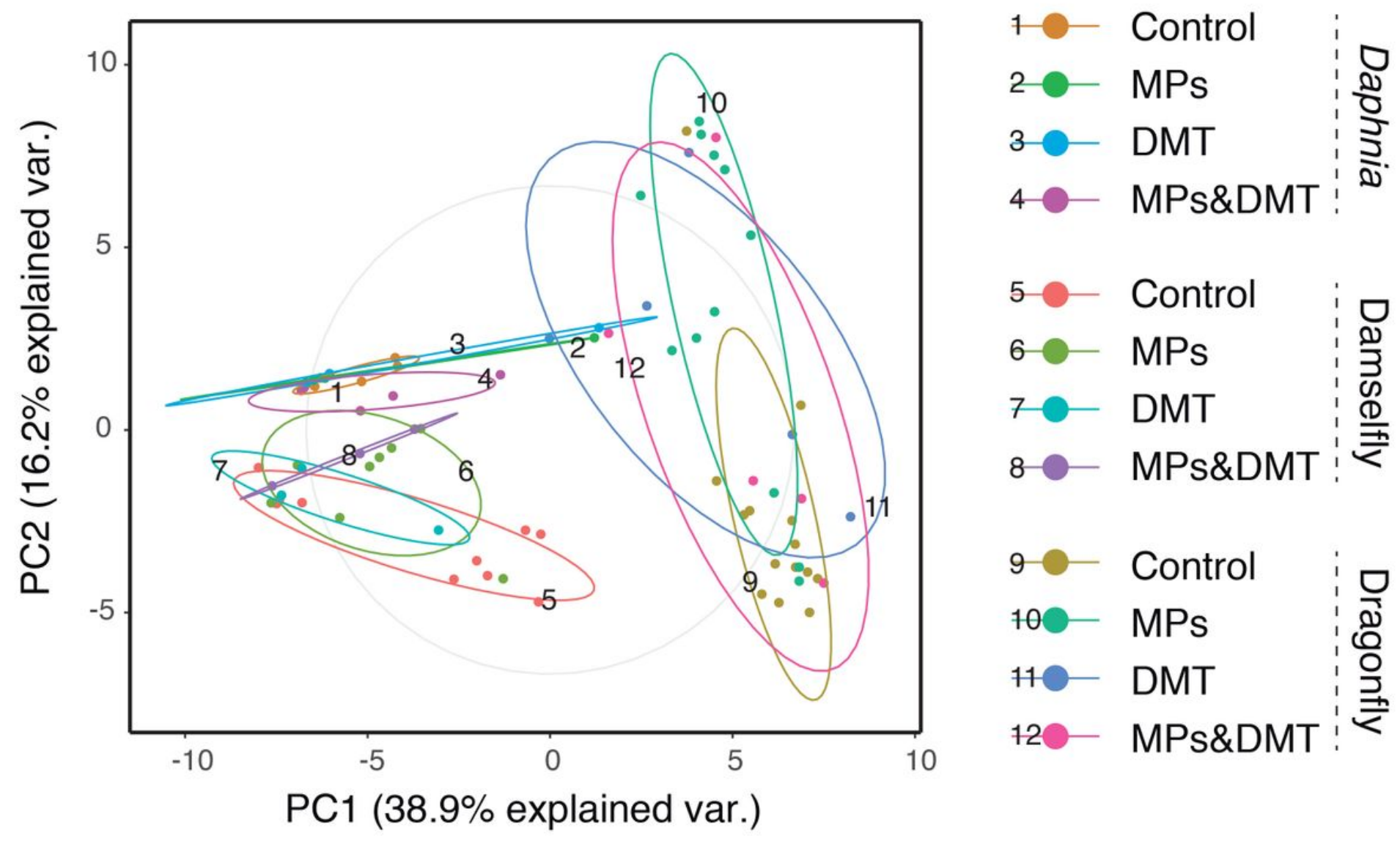

\section{Figure 3}

Principal Coordinates Analysis showing the microbial composition clusters of the microbiome of Daphnia, the damselfly and the dragonfly. The microbial composition in each species is coded following the exposure treatment to microplastics (MPs), the pesticide deltamethrin (DMT), a combination of both, and without either of them (Control). 


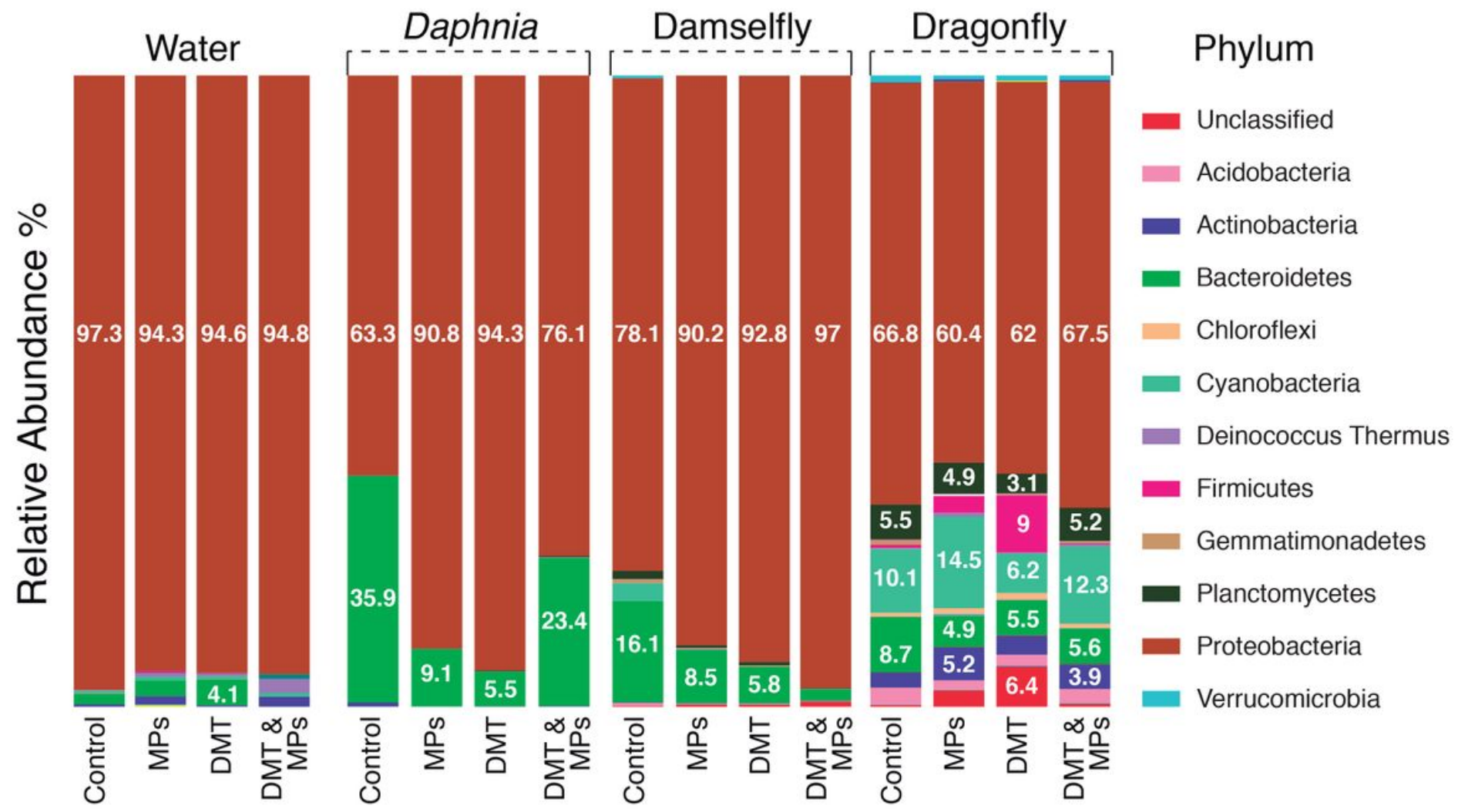

Figure 4

Relative abundance of the microbiome of Daphnia, the damselfly and the dragonfly, including the relative abundance of the water microbiota extracted from the filters. The exposure treatments were: microplastics (MPs), the pesticide deltamethrin (DMT), a combination of MPs and DMT, and the Control group (no exposure to either MPs or DMT). 


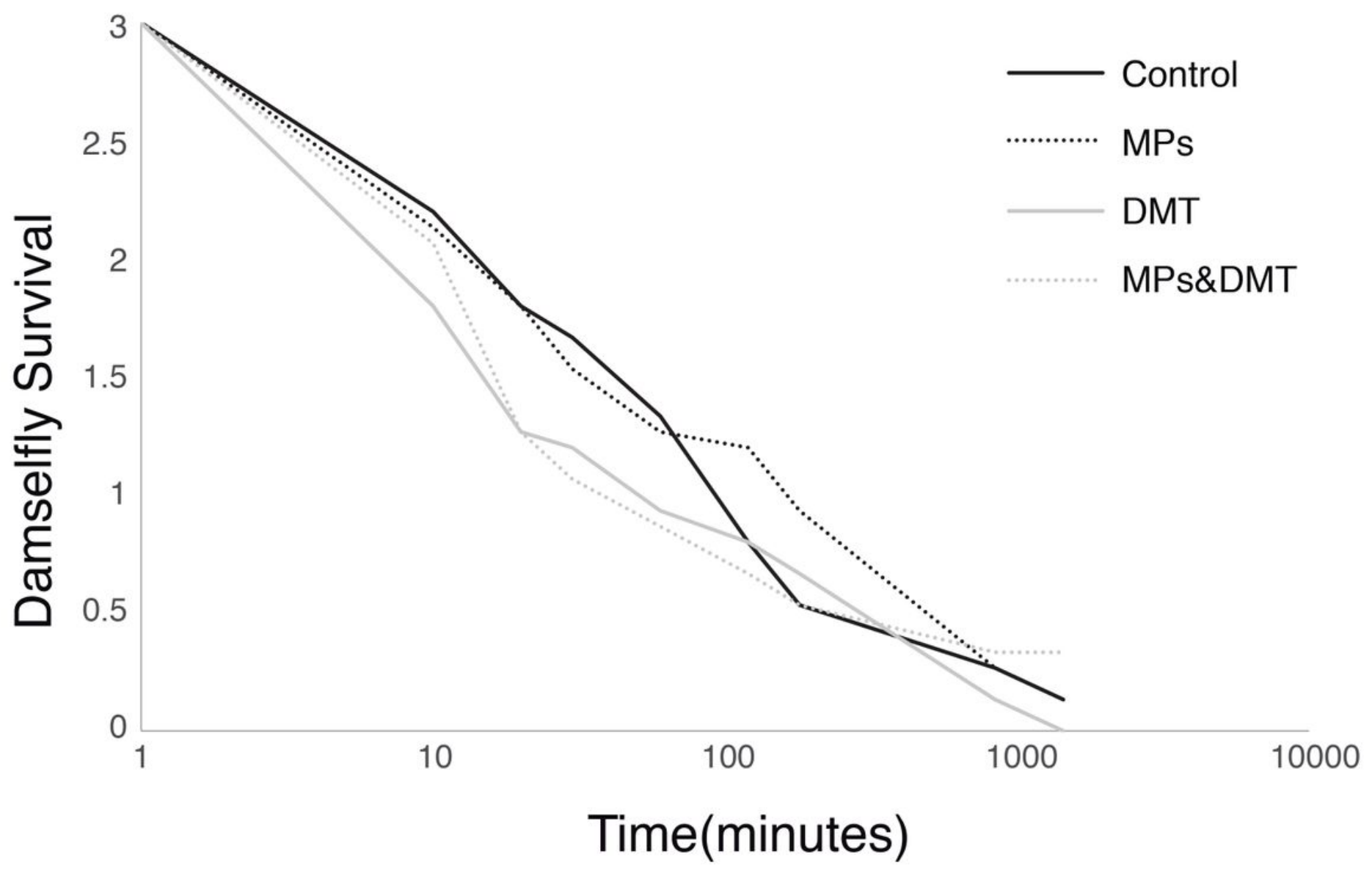

Figure 5

Damselfly survival from dragonfly predation over time when the damselfly larvae were exposed to microplastics (MPs), the pesticide deltamethrin (DMT), to both MPs and DMT (MPS\&DMT) or to none of these stressors (Control). 